\title{
The Role of Recession Forecasts and F-score in Predicting Credit Risks
}

\author{
Kevin Chi-Keung Li \\ The Open University of Hong Kong
}

\author{
Eric C.Y. Ng \\ The Hong Kong University of Science and Technology \\ Bob Wai-Ho Leung \\ The Open University of Hong Kong
}

\begin{abstract}
An accurate forecast for corporate default risk is crucial for financial institutions to effectively quantify potential expected and unexpected borrower losses. This paper develops a logistic regression model to simultaneously examine the roles of firm-specific fundamentals and economic outlook in predicting corporate default risk. The model is estimated using U.S. listed non-financial firms over the 1997-2009 period. The empirical findings suggest that economic outlook captured by recession probability forecast, firm-specific fundamental factors measured by the Z-score and F-score, and the interaction between economic outlook and firm-specific fundamental factors play statistically significant roles in predicting bankruptcy risk. The model exhibits relatively high levels of goodness-of-fit and classification ability, and low levels of forecast error.
\end{abstract}

Keywords: credit risks, recession forecasts, Piotroski's F-score

\section{INTRODUCTION}

An important issue in credit risk management is for financial institutions to put aside adequate reserves and economic capital to cover any expected and unexpected losses due to potential borrower defaults. Accordingly, it is crucial for financial institutions to accurately and effectively quantify both expected and unexpected losses, which are generally a function of default probability, exposure at default, and loss given default. This paper focuses on the determinants of default probability and proposes an empirical model that is capable of predicting bankruptcy risks with relatively low levels of forecast error and high levels of classification ability. ${ }^{1}$ The proposed model simultaneously examines the roles of firmspecific fundamental factors and economic outlook in predicting bankruptcy risks. The model is novel in that it (a) uses an alternative measure for evaluating firm-specific characteristics known as the F-score (Piotroski, 2000), which is widely used in the accounting and financial literature to assess financial strength and develop investment strategies, but is relatively less popular in the credit risk modeling literature; (b) compares the predictive ability of the Z-score (Altman, 1968), a well-known rating model in the credit risk modeling literature used to distinguish between default and non-default firms, with that of the F-score; (c) uses a forward-looking variable, namely recession probability forecast, to capture 
economic outlook; and (d) studies the interaction between firm-specific fundamentals and economic outlook in forecasting default risks.

We use a logistic regression framework to incorporate the firm-specific factors (both the F-score and Z-score), economic outlook variable (recession probability forecast), and interaction term between the variables for a firm's fundamentals and economic outlook. We estimate the empirical model using U.S. listed non-financial firms over the 1997-2009 period. The regression analysis indicates that economic outlook (captured by the recession probability forecast), firm-specific fundamental factors (measured by both the Z-score and F-score), and the interaction between economic outlook and a firm's fundamentals play statistically significant roles in predicting corporate default risks. On the one hand, a gloomy economic outlook as reflected by an increase in the recession probability forecast tends to increase corporate default risks. On the other hand, firms with strong fundamentals and a high Z-score or F-score also tend to have low bankruptcy risks. The negative coefficient on the interaction term between the Zscore and recession probability forecast further implies that firms with strong fundamentals (with a high Z-score) could counterbalance the negative effect of economic recession on default risks. Both in-sample and out-of-sample analyses further suggest that the proposed model exhibits a relatively high goodnessof-fit (as implied by McFadden's pseudo R-squared), low forecast errors (as measured by the Brier score, log probability score (LPS), and Bayesian information criterion (BIC)), and high classification ability (as reflected by the area under the receiver operating characteristic curve (AUC) and the overall accuracy ratio), compared with the other models under consideration (including a simple model with the Z-score and firm size only, with the F-score and firm size only, and with economic outlook and firm size only).

This paper relates to the literature on bankruptcy prediction models. Before the use of logistic regression became popular, multiple discriminant analysis (MDA), first utilized by Altman (1968) to predict bankruptcy using a set of financial ratios, was widely adopted in bankruptcy prediction studies. Ohlson (1980) was the first to propose using conditional logistic regression to predict bankruptcy. His study argues that logistic regression can avoid several restrictive assumptions of MDA. Particularly, logistic regression can work with disproportional samples and dummy independent variables (Ohlson, 1980; Altman and Sabato, 2007). Since that study, logistic regression has become the prevalent methodology in the bankruptcy prediction literature (Plat and Platt, 1990; Richardson et al., 1998; Nam and Jinn, 2000; Kuo et al., 2003; Arslan and Karan, 2009; Dainelli et al., 2013; Muscettola, 2013; Brédart, 2014). However, the early versions of the logistic models were generally "static" because the estimation of the models accounted for only one observation for each firm, thus ignoring changes in a firm's characteristics over time (Shumway, 2001). Shumway (2001) proposes a discrete-time hazard model that uses all available observations of each firm to predict bankruptcy probability. He finds that the hazard model can produce consistent estimation and exhibits a better holdout sample performance. In fact, Shumway (2001) and Nam et al. (2008) further demonstrate that multi-period logistic regression is equivalent to the discrete-time hazard model. Given these advantages, the recent literature considers it favorable to use multi-period logistic regression to predict bankruptcy probability. A number of studies apply a multi-period logistic regression technique to predict the bankruptcy probability of small and medium-sized enterprises (Altman and Sabato, 2007; Altman et al., 2010; Pederzoli, et al., 2013; Gupta et al., 2014; Filipe et al., 2016). In addition, a few studies focus on listed companies (Wu et al., 2010; Tinoco and Wilson, 2013). In general, the literature focuses on the role of various components of firmspecific characteristics (related to financial or non-financial information) in predicting default risks.

A few recent studies, however, attempt to incorporate macroeconomic information (in addition to firm-specific fundamentals) to predict bankruptcy probability. Richardson et al. (1998) find that the inclusion of variables that control for failure occurring either during or outside of an economic recession can improve the predictive power of the failure prediction model. They also find that a failure prediction model is sensitive to the addition of variables that control for the knowledge that financial statement data represent company operations during a recession. Bonfim (2009) uses a random-effect probit model to predict bankruptcy probability for Portuguese firms. She finds some empirical evidence (depending on the number of years the variables are lagged) that interest rates on loans to firms, yield spread slopes, loan growth, and coincident economic activity indicators have statistically significant effects on default 
probability. Using data from U.K. listed companies and panel logistic regression, Tinoco and Wilson (2013) find that both the retail price index and 3-month real U.K. Treasury bill rate are statistically significant predictors of financial distress. Mare (2015) includes the interbank deposit rate, region employment rate, and an indicator of regional competition in the banking industry to predict the bankruptcy probability of cooperative banks in Italy, and concludes that the macroeconomic variables are statistically significant.

Our paper also contributes to the recent literature on the role of macroeconomic information in predicting bankruptcy risks. However, our approaches differ from the aforementioned studies in several important ways. First, unlike the literature that generally examines the predictive role of a limited set of economic variables related to real output and income, labor and monetary statistics, prices, and interest rates, we investigate the predictive power of a forward-looking variable capturing economic outlook. The forward-looking variable refers to a recession probability forecast, which is obtained from a sophisticated model that effectively encompasses many economic and financial variables with mixed sampling frequencies (low-frequency quarterly/monthly data and high-frequency weekly/daily data). In fact, the forward-looking nature of many real-time financial variables (e.g., daily stock prices, exchange rates, and interest rates) means that they may contain valuable information about the future state of the economy. As shown later in our analysis, the forecast for economic outlook (captured by the recession probability forecast) is highly relevant for predicting the default risks of firms. Second, we study not only the direct effect of economic outlook on default risks, but also its indirect effect. We do so by analyzing the interaction between the economic outlook variable and firm-specific fundamental factor. The interaction analysis enables us to estimate the threshold (or minimum) level of a firm's financial strength that is capable of weathering the negative impact of an upcoming economic downturn. Third, we conduct out-ofsample analysis using the holdout sample in 2008 and 2009. This allows us to evaluate whether the proposed model performed well during the last financial crisis, which eventually caused the Great Recession around the globe. Fourth, we evaluate the predictive performance of an alternative measure for firm-specific fundamentals, namely the F-score proposed by Piotroski (2000), and compare it with the popular Z-score proposed by Altman (1968) for credit rating. We find that the F-score can complement the Z-score to improve the predictive power of the model.

This paper is also related to the literature on the role of the F-score in fundamental analysis and investment strategies. The F-score is primarily utilized to screen financially strong firms in the portfolios of high book-to-market-value firms. It is an accounting-based fundamental analysis conducted to examine a firm's financial strength. It contains nine individual binary variables: four reflect a firm's profitability; three indicate a firm's leverage, liquidity, and source of funds; and the last two reflect a firm's operating efficiency. The F-score is a composite score summing the value of all nine variables. A higher composite score represents a firm's current stronger financial position and in turn may reflect better future performance and higher stock returns. By comparing mean market-adjusted returns on a portfolio containing only high F-score firms with those on a complete portfolio of high book-market firms, Piotroski (2000) illustrates that the former portfolio can earn statistically significant $7.5 \%$ higher mean returns than the latter portfolio. Moreover, by controlling firm size, the book-to-market ratio, the momentum effect, and other variables that may otherwise affect the returns of a firm, the author finds that the correlation between the F-score and 1-year market-adjusted returns is still statistically significant and positive in the regression analyses. Various studies focus on the performance of F-score-based investment strategies (Hyde, 2014; James et al., 2014; Krauss et al., 2015; Geyfman et al., 2016; Amor-Tapia and Tascon, 2016). Choi and Sias (2012) show that a firm's F-score may forecast not only its stock return, but also the future demand of institutional investors for the stock. Piotroski and So (2012) reveal that the value/glamour effect exists mostly for firms with ex-ante discrepancies between market expectations of their performance (book-to-market ratio) and their financial strength (F-score). As mentioned before, our paper differs from other studies by exploring the role of the F-score in predicting default risks.

The remainder of this paper is organized as follows. Section 2 specifies the default prediction model. Section 3 describes the data and variable construction. The in-sample and out-of-sample estimation results are then presented in Section 4. Section 5 concludes the paper. 


\section{THE DEFAULT PREDICTION MODEL}

The dependent variable $Y_{t}^{i}$ is a binary indicator that equals one if company $i$ defaults in time $t$ and zero if it does not default. Conditional on information set $\Omega_{t-1}^{i}$ at time $t-1, Y_{t \mid t-1}^{i}$ has a Bernoulli distribution: $Y_{t}^{i} \mid \Omega_{t-1}^{i} \sim B\left(p_{t}\right)$. Let us define $E_{t-1}($.$) and P_{t-1}($.$) as the conditional expectation and$ probability, respectively, given $\Omega_{t-1}^{i}$. The conditional expectation of $Y_{t}^{i}$ can then be given by $E_{t-1}\left(Y_{t}^{i}\right)=$ $P_{t-1}\left(Y_{t}^{i}=1\right)=P_{t}^{i}$. We assume that $P_{t}^{i}$ has the following logit specification:

$P_{t}^{i}=\frac{1}{1+e^{-\pi_{t}^{i}}}$

where $\pi_{t}^{i}$ is a function of the explanatory variables explained as follows.

The default prediction model includes firm-specific fundamental factors (Z-score and F-score), forward-looking economic outlook (as captured by recession probability forecasts), and the interaction between firm-specific fundamental factors and economic outlook. $\pi_{t}^{i}$ is given by

$\pi_{t}^{i}=\beta_{0}+\beta_{1}\left(\text { Firm }_{\text {size }}\right)_{t-1}^{i}+\beta_{2}\left(Z_{\text {score }}\right)_{t-1}^{i}+\beta_{3}\left(F_{\text {score }}\right)_{t-1}^{i}$

$+\beta_{4}\left(\right.$ Recession Forecast $_{t}$

$+\beta_{5}\left(Z_{-} \text {score }\right)_{t-1}^{i} \times(\text { Recession_Forecast })_{t}$,

where Firm_size is the natural logarithm of total assets, $Z_{-}$score and $F_{-}$score are Altman's Z-score (1968) and Piotroski's F-score (2000), respectively, Recession_Forecast is the one-period-ahead forecast for recession probability made at time $t-1$.

The data for recession probability forecasts (Recession_Forecast) are based on the recession forecasting model of Lai and $\mathrm{Ng}$ (2020). Their recession forecasting model combines an autoregressive logit model capturing the autocorrelation of business cycles, a dynamic factor model encompassing many economic and financial variables, and a mixed data sampling regression (MIDAS) approach incorporating common factors with mixed sampling frequencies.

Specifically, the monthly recession probability $p_{\tau+N}$ is defined as the probability that a recession will occur in the next $N$ months. It has the following logit specification:

$p_{\tau+N}=\frac{1}{1+e^{-\eta} \tau^{\prime}}$

and the functional form of $\eta_{t}$ is given by

$\eta_{\tau}=\rho \eta_{\tau-1}+\beta^{\prime} F_{\tau}+(1-\rho L) \sum_{k=1}^{K} \gamma_{k} B_{k}\left(L^{1 / w} ; \theta_{k}\right) f_{k, \tau}^{(w)}$

where $F_{\tau}$ is the vector of monthly common factors, $f_{k, \tau}^{(w)}$ is the $k^{\text {th }}$ high-frequency (weekly) common factor, and $K$ is the number of high-frequency common factors. Let $F_{\tau}^{w}$ be the vector of all of the highfrequency common factors. Furthermore, $B_{k}\left(L^{1 / w} ; \theta_{k}\right)=\sum_{i=1}^{w} b\left(i ; \theta_{k}\right) L^{(i-1) / w}$ and $L^{s / w} f_{k, \tau}^{(w)}=$ $f_{k, \tau-s / w}^{(w)}$, where $\tau$ refers to the basic time unit (i.e., monthly), $w$ is the higher sampling frequency (weekly factors), $L^{1 / w}$ is the lag operator that operates at a higher frequency, and $b\left(i ; \theta_{k}\right)$ assigns weights to the $i^{\text {th }}$ most recent weekly observation and is parameterized by a two-parameter exponential Almon lag function (Ghysels et al., 2004, 2006) as

$b\left(i ; \theta_{k}\right)=\frac{\exp \left(\theta_{k, 1} i+\theta_{k, 2} i^{2}\right)}{\sum_{i=1}^{W} \exp \left(\theta_{k, 1} i+\theta_{k, 2} i^{2}\right)}$. 
The common factors in (4) are extracted from the static representation of the dynamic factor models using principal component analysis (PCA), given by

$X_{\tau}=\Lambda_{1} F_{\tau}+\varepsilon_{\tau}$

$X_{\tau}^{w}=\Lambda_{2} F_{\tau}^{w}+\varepsilon_{\tau}^{w}$

where $X_{\tau}$ and $X_{\tau}^{w}$ are vectors of the monthly and higher-frequency variables, respectively.

Lai and $\mathrm{Ng}$ (2020) find that the preceding recession forecasting model achieves better in-sample and out-of-sample performance in predicting U.S. recessions than do some of the popular models in the literature. The model not only generates more accurate recession forecasts over various time horizons (from 1 to 12 months), but also triggers stronger and earlier signals for the turning points of business cycles.

Lai and $\mathrm{Ng}$ (2020) estimate the monthly recession probability $p_{\tau+N}$ over different forecasting months $(N=1,3,6,9,12)$. As we estimate our default prediction model using annual data, we use the estimated recession probability for $N=12$. Furthermore, we convert the original monthly recession probability forecasts into annual forecasts by averaging the monthly forecasts over a 12-month horizon. Hence, Recession_Forecast at any time $t$ is given by

Recession_Forecast $=\frac{1}{12} \sum_{\tau=1}^{12} p_{\tau+12}$.

For example, Recession_Forecast for 1997 is the average of the monthly forecasts for $p_{\tau+12}$ from December 1996 to November 1997.

It should be noted that when $\beta_{3}=\beta_{4}=\beta_{5}=0$ in Eq. (2), the default prediction model effectively becomes a credit risk regression model using Altman's (1968) Z-score and controlling for firm size. We refer to it as Model 1:

$\pi_{t}^{i}=\alpha_{0}+\alpha_{1}(\text { Firm_size })_{t-1}^{i}+\alpha_{2}\left(Z_{-} \text {score }\right)_{t-1}^{i}$.

When $\beta_{2}=\beta_{4}=\beta_{5}=0$ in Eq. (2), the default prediction model includes only the F-score and firm size as the explanatory variables for credit risk. It becomes Model 2:

$\pi_{t}^{i}=\gamma_{0}+\gamma_{1}(\text { Firm_size })_{t-1}^{i}+\gamma_{2}\left(F_{-} \text {score }\right)_{t-1}^{i}$.

When $\beta_{2}=\beta_{3}=\beta_{5}=0$ in Eq. (2), the default prediction model includes only the economic outlook (captured by the recession forecast) and firm size as the determinants of credit risk. We call it Model 3:

$\pi_{t}^{i}=\delta_{0}+\delta_{1}(\text { Firm_size })_{t-1}^{i}+\delta_{2}(\text { Recession_Forecast })_{t}$.

Finally, the original model in Eq. (2) is referred to as Model 4. In the next section, we compare the insample and out-of-sample performance of the four models in predicting default risks.

\section{DATA}

We develop the sample using Bloomberg's Equity Screening. We include all of the American firms listed on NYSE, AMEX, NASDAQ Global Select, and NASDAQ Global Market over the 1997-2009 period in the sample. Firms with total assets (adjusted to the U.S. GDP deflator) less than or equal to US\$100 million are dropped. We also exclude all financial firms (SIC code between 6000 and 6999). All of the annual accounting and market data from each firm-year in the sample are collected from Bloomberg. 
In this study, firms are defined as bankrupt if they filed for any type of bankruptcy within our sample period. Bankruptcy data, including data on the type of bankruptcy and the announced and effective dates of bankruptcy, are downloaded from Bloomberg's Company Bankruptcy Filing. We match this bankruptcy data with our sample to identify bankrupt firms. For firms that filed for bankruptcy multiple times, we count only their first bankruptcy filing. We treat the last firm-year of bankrupt firms in the sample as the bankruptcy firm-year. In contrast, all of the firm-years before the bankruptcy firm-year are considered as non-bankrupt. Moreover, when the lag between the last firm-year of a bankrupt firm in the sample and the announced date of bankruptcy exceeds five years, we treat this last firm-year as the nonbankruptcy firm-year. All observations of a bankrupt firm after the bankruptcy firm-year are eliminated. In other words, for a bankrupt firm, its last observation is its bankruptcy firm-year.

Our final sample contains 4,368 firms that contribute 27,428 firm-years. Of these, 453 firms are identified as bankrupt. In total, bankrupt firms contribute 453 bankruptcy firm-years and 1,402 nonbankruptcy firm-years. Data from 2008 and 2009 are retained as the holdout sample. The in-sample includes 22,957 non-bankruptcy firm-years and 404 bankruptcy firm-years. The holdout sample consists of 4,018 non-bankruptcy firm-years and 49 bankruptcy firm-years. Table 1 summarizes the bankruptcy rate of our sample. The average bankruptcy rate during the sample period is $1.65 \%$. Although the bankruptcy rate reached its peak at $3.6 \%$ in 2000 , it dropped subsequently to $0.53 \%$ in 2005 . The bankruptcy rate then increased to $1.78 \%$ in 2008 due to the outbreak of the Great Recession.

TABLE 1

DESCRIPTION OF THE SAMPLE

\begin{tabular}{ccccc}
\hline Year & Bankrupt & Non-bankrupt & Total & Bankruptcy rate (\%) \\
\hline 1997 & 36 & 2,283 & 2,319 & 1.55 \\
1998 & 32 & 2,069 & 2,101 & 1.52 \\
1999 & 35 & 2,098 & 2,133 & 1.64 \\
2000 & 78 & 2,091 & 2,169 & 3.60 \\
2001 & 66 & 2,182 & 2,248 & 2.94 \\
2002 & 45 & 2,096 & 2,141 & 2.10 \\
2003 & 24 & 2,020 & 2,044 & 1.17 \\
2004 & 25 & 1,963 & 1,988 & 1.26 \\
2005 & 11 & 2,052 & 2,063 & 0.53 \\
2006 & 22 & 2,072 & 2,094 & 1.05 \\
2007 & 30 & 2,031 & 2,061 & 1.46 \\
2008 & 37 & 2,047 & 2,084 & 1.78 \\
2009 & 12 & 1,971 & 1,983 & 0.61 \\
Total & 453 & 26,975 & 27,428 & 1.65 \\
\hline
\end{tabular}

All of the accounting and market information for each firm-year is collected from Bloomberg. Our bankruptcy prediction estimation models incorporate Altman's Z-score (1968), Piotroski's F-score (2000), and the economic outlook variable. We lag all of the data by 1 year to predict the current bankruptcy probability.

We follow the methodologies of Altman (1968) and Piotroski (2000) to construct the Z-score and Fscore for each firm-year in our sample. Altman (1968) conducts multiple discriminant analysis to estimate a summary index (Z-score). The Z-score is used to discriminate between bankrupt and non-bankrupt firms in a sample of listed companies. It includes five financial ratios as variables with a discriminant coefficient attached to each variable. The five financial ratios are (1) Working capital/Total assets $\left(Z_{1}\right)$, (2) Retained earnings/Total assets $\left(Z_{2}\right)$, (3) Earnings before interest and taxes/Total assets $\left(Z_{3}\right)$, (4) Market value of equity/Book value of total debt $\left(Z_{4}\right)$, and (5) Sales/Total assets $\left(Z_{5}\right)$. In the original setting, the $Z$-score was obtained using the following equation: $Z=0.012 Z_{1}+0.014 Z_{2}+0.033 Z_{3}+$ $0.006 Z_{4}+0.999 Z_{5}$. The equation was subsequently modified and became $Z=1.2 Z_{1}+1.4 Z_{2}+3.3 Z_{3}+$ 
$0.6 Z_{4}+1.0 Z_{5}$. In our study, we adopt the modified version and estimate the Z-score for each firm-year. Altman (1968) concludes that firms with a Z-score lower than 1.81 can be classified as bankrupt while those with a Z-score higher than 2.99 are non-bankrupt. Firms with a Z-score in the range of 1.81-2.99 are unclassified. We expect the coefficient of the Z-score in our models to have a negative sign.

Piotroski's F-score (2000) is primarily used to screen the "winners" in a portfolio of high book-tomarket firms. The F-score contains nine distant binary signals that can reflect a firm's profitability, leverage, liquidity and source of funds, and operating efficiency. The four signals representing profitability includes (1) ROA (Net income before extraordinary items/One-year lagged total assets), (2) CFO (Cash flow from operation/One-year lagged total assets), (3) Change in ROA (ROA in current period minus ROA in the lagged one period), and (4) ACCRUAL (ROA minus CFO). If the firm has a positive ROA and CFO values and a change in ROA or a negative ACCRUAL value, the value of the respective binary signal is equal to one.

Three variables reflecting a firm's leverage, liquidity, and source of funds are (5) Change in longterm debt level (Difference of ratio of total long-term debt to average total assets between the current and lagged one periods), (6) Change in current ratio (Ratio of current assets to current liabilities in current period minus the ratio in the lagged one period), and (7) Firm's issuance of common equity (Number of outstanding shares in the current period minus the number in the lagged one period). The corresponding binary signal is equal to one if the value in (5) is negative, that in (6) is positive, and that in (7) is less than or equal to zero.

The last two variables reflect the firm's operating efficiency. They are (8) Change in gross margin ratio (Gross margin ratio in the current period minus the ratio in the lagged one period) and (9) Change in asset turnover ratio (Ratio of total sales in the lagged one period to total assets in the current period minus the ratio in the lagged one period). If the firm has positive values in (8) and (9), the two respective binary signals are equal to one.

We sum the value of the nine binary signals of each firm-year to obtain the F-score for all firm-years. The F-score ranges between 0 and 9. A higher F-score indicates that a firm has a stronger financial condition. We expect that the F-score is negatively related to default probability.

Table 2 provides the descriptive statistics of corporate fundamental variables. On average, the Z-score of non-bankrupt firms is 4.224, which is six times higher than the Z-score of bankrupt firms. Except for $\mathrm{Z} 5$, non-bankrupt firms have higher values in all of the individual components of the $\mathrm{Z}$-score than those of bankrupt firms. In terms of the F-score, non-bankrupt firms also outperform bankrupt firms. Nonbankrupt firms have higher mean values in eight of the nine F-score components. Statistically significant differences in the mean values of the Z-score and F-score between non-bankrupt and bankrupt firms indicate that both the Z-score and F-score can discriminate the financially healthy firms from the firms that are in financial trouble.

TABLE 2

DESCRIPTIVE STATISTICS OF CORPORATE FUNDAMENTAL VARIABLES

\begin{tabular}{|c|c|c|c|c|c|c|c|c|c|}
\hline & \multicolumn{3}{|c|}{ Bankrupt } & \multicolumn{3}{|c|}{ Non-bankrupt } & \multicolumn{3}{|c|}{ Univariate analysis } \\
\hline Variables & Obs. & $\begin{array}{l}\text { Mean } \\
\text { (1) }\end{array}$ & Std. dev. & Obs. & $\begin{array}{l}\text { Mean } \\
(2)\end{array}$ & Std. dev. & $\begin{array}{c}\text { Diff }=(2) \\
-(1)\end{array}$ & t-ratio & p-value \\
\hline $\begin{array}{l}\text { Total } \\
\text { Assets }\end{array}$ & 371 & $1,874.50$ & $6,002.56$ & 26,477 & $4,411.48$ & $20,187.56$ & $2,536.97$ & 2.42 & 0.0156 \\
\hline \multicolumn{10}{|c|}{ Altman's Z-score (1968) } \\
\hline$Z_{1}$ & 371 & -0.031 & 0.436 & 26,452 & 0.218 & 0.220 & 0.249 & 21.20 & 0.0000 \\
\hline$Z_{2}$ & 371 & -0.415 & 1.443 & 26,463 & -0.049 & 1.057 & 0.366 & 6.58 & 0.0000 \\
\hline $\mathrm{Z}_{3}$ & 371 & -0.083 & 0.282 & 26,460 & 0.067 & 0.169 & 0.151 & 16.81 & 0.0000 \\
\hline $\mathrm{Z}_{4}$ & 367 & 0.568 & 1.421 & 26,008 & 4.475 & 10.927 & 3.901 & 6.85 & 0.0000 \\
\hline $\mathrm{Z}_{5}$ & 371 & 1.155 & 0.942 & 26,465 & 1.105 & 0.875 & -0.050 & -1.10 & 0.2730 \\
\hline Z-score & 367 & 0.596 & 2.948 & 25,959 & 4.224 & 6.895 & 3.628 & 10.08 & 0.0000 \\
\hline
\end{tabular}




\begin{tabular}{lccccccccc}
\hline \multicolumn{2}{l}{ Piotroski's } & F score (200) & & & & & & & \\
$\mathrm{F}_{1}$ & 366 & 0.156 & 0.363 & 26,136 & 0.762 & 0.426 & 0.606 & 27.06 & 0.0000 \\
$\mathrm{~F}_{2}$ & 362 & 0.547 & 0.498 & 26,069 & 0.882 & 0.323 & 0.335 & 19.40 & 0.0000 \\
$\mathrm{~F}_{3}$ & 296 & 0.314 & 0.465 & 23,275 & 0.491 & 0.500 & 0.177 & 6.06 & 0.0000 \\
$\mathrm{~F}_{4}$ & 362 & 0.917 & 0.276 & 26,060 & 0.853 & 0.354 & -0.064 & -3.43 & 0.0006 \\
$\mathrm{~F}_{5}$ & 292 & 0.500 & 0.501 & 23,109 & 0.524 & 0.499 & 0.024 & 0.81 & 0.4163 \\
$\mathrm{~F}_{6}$ & 362 & 0.315 & 0.465 & 26,061 & 0.493 & 0.500 & 0.178 & 6.73 & 0.0000 \\
$\mathrm{~F}_{7}$ & 359 & 0.209 & 0.407 & 25,619 & 0.321 & 0.467 & 0.112 & 4.53 & 0.0000 \\
$\mathrm{~F}_{8}$ & 341 & 0.337 & 0.473 & 24,887 & 0.495 & 0.500 & 0.158 & 5.81 & 0.0000 \\
$\mathrm{~F}_{9}$ & 301 & 0.402 & 0.491 & 23,310 & 0.481 & 0.500 & 0.079 & 2.73 & 0.0063 \\
$\mathrm{~F}$-score & 272 & 3.816 & 1.504 & 21,679 & 5.372 & 1.610 & 1.56 & 15.85 & 0.0000 \\
\hline
\end{tabular}

The data used to estimate the recession forecasting model are based on Lai and $\mathrm{Ng}$ (2020). The time series for the dependent variable are constructed using the recession dates identified by the National Bureau of Economic Research. The monthly data of 141 economic and financial variables over the 1964-2010 period are used to extract the monthly common factors $F_{\tau}$. The variables can be grouped into 14 main categories: real output; real income; employment and hours; real retail, manufacturing, and trade sales; consumption; housing starts and sales; real inventories and inventory-sale ratios; orders and unfilled orders; stock prices; exchange rates; interest rates; money and credits; price indices; average hourly earnings; and miscellaneous. Similarly, the weekly data of 118 economic and financial variables over the 1973-2010 period are used to extract the weekly common factors $F_{\tau}^{w}{ }^{2}$ The variables are classified into six main categories: yields on T-bonds and T-bills, state and local government bonds, and corporate bonds; money market interest rates; bank credits and loans and financial condition indices; stock market indices; exchange rates; and unemployment-related statistics. The data are taken from various sources, including the IHS Global Insight Database, the Federal Reserve Economic Data of the Federal Reserve Bank of St. Louis, the Data Download Program of the Board of Governors of the Federal Reserve System, the Bloomberg Database, and Yahoo Finance.

\section{ESTIMATION RESULTS}

\section{Evaluation Statistics}

We use different evaluation statistics to assess the performance of the aforementioned four models in predicting default risks. These include McFadden's pseudo R-squared, the Brier score, the LPS, the BIC, the AUC, and the overall accuracy ratio. McFadden's pseudo R-squared is a kind of goodness-of-fit measure. The Brier score and LPS are regarded as proper scoring rules for binary variables (Lahiri and Yang, 2013). The BIC is generally considered the most consistent criteria with the largest penalty factor. The AUC is widely used in the literature on credit risk modeling to assess the overall ability to classify default and non-default signals. The overall accuracy ratio, defined as one minus the average of the TypeI and Type-II error rates, is also used in the literature as a complement to the AUC.

\section{In-sample Results}

In the in-sample analysis, we pool all of the firm-year observations over the 1997-2007 period and estimate the four models as described in Section 2. In each model, we include a constant term and eight industry dummy variables. The industry classifications are based on the Bloomberg Industry Classification System, which classifies firms' general business activities into 10 sectors, including communications, consumer discretionary, consumer staples, energy, financials, health care, industrials, materials, technology, and utilities. We exclude financials from our dataset and choose communications as the omitted industry dummy in the regression analysis (to avoid perfect collinearity). The industry dummy variables are included to control for the variations in the industry default rates. For example, our sample data suggest that firms in the communications sector have the highest average default rate of $3.6 \%$ and that those in the utilities sector have the lowest average default rate of $0.5 \%$ over the 1997-2009 period. $^{3}$ 
Table 3 summarizes the in-sample estimation results. In all four of the model specifications, the coefficient on firm size is significantly negative. In other words, small firms tend to have higher default rates than large firms. Model 1 further suggests that the Z-score is also a significant predictor of default. Firms with a high Z-score tend to have lower default rates than firms with a low Z-score. This result is consistent with the general finding in the literature that the use of the Z-score (Altman, 1968) or its second-generation zeta model (Altman et al., 1977) can to some extent effectively distinguish between default and non-default firms. It also explains why practitioners around the world are still using the Zscore and zeta models (Altman, 2000).

TABLE 3

IN-SAMPLE ESTIMATION RESULTS

\begin{tabular}{|c|c|c|c|c|}
\hline & Model 1 & Model 2 & Model 3 & Model 4 \\
\hline \multicolumn{5}{|l|}{ Explanatory variables } \\
\hline Firm size & $\begin{array}{c}-0.2315 \\
(0.0000)\end{array}$ & $\begin{array}{r}-0.1410 \\
(0.0060)\end{array}$ & $\begin{array}{l}-0.2150 \\
(0.0000)\end{array}$ & $\begin{array}{l}-0.1726 \\
(0.0010)\end{array}$ \\
\hline Z-score & $\begin{array}{c}-0.0891 \\
(0.0120)\end{array}$ & & & $\begin{array}{c}-0.1731 \\
(0.0000)\end{array}$ \\
\hline F-score & & $\begin{array}{r}-0.5280 \\
(0.0000)\end{array}$ & & $\begin{array}{c}-0.4553 \\
(0.0000)\end{array}$ \\
\hline Recession forecast & & & $\begin{array}{r}0.6729 \\
(0.0000)\end{array}$ & $\begin{array}{r}0.7124 \\
(0.0030)\end{array}$ \\
\hline$Z$-score $\times$ Recession forecast & & & & $\begin{array}{c}-0.1454 \\
(0.0060)\end{array}$ \\
\hline Pseudo R-squared & 0.0420 & 0.1090 & 0.0317 & 0.1423 \\
\hline Brier score & 0.0174 & 0.0137 & 0.0171 & 0.0137 \\
\hline LPS & 0.0855 & 0.0666 & 0.0853 & 0.0642 \\
\hline $\mathrm{BIC}$ & 3640 & 2161 & 3699 & 2113 \\
\hline AUC & 0.7139 & 0.7858 & 0.6587 & 0.8284 \\
\hline Overall accuracy ratio & 0.6617 & 0.7182 & 0.6279 & 0.7543 \\
\hline Number of observations & 20,638 & 15,420 & 21,042 & 15,407 \\
\hline
\end{tabular}

Notes: All regression models include a constant term and industry dummy variables. Numbers in parenthesis denote p-values of the corresponding coefficients. LPS stands for log probability score, BIC for Bayesian information criterion, and AUC for area under the receiver operating characteristic (ROC) curve.

Model 2 indicates that the F-score also plays a significant role in predicting the default rate. Firms with a high F-score tend to exhibit lower default rates than firms with a low F-score. Interestingly, the use of the F-score increases the goodness-of-fit of the default prediction model (with a pseudo R-squared of 0.0420 in model 1 versus one of 0.1090 in model 2) and decreases the forecast errors (with a reduction of $21-41 \%$ of the forecast errors measured by the Brier score, LPS, and BIC). In terms of the overall ability to classify default and non-default signals, the F-score model also outperforms the Z-score model with a higher AUC (0.7139 in model 1 versus 0.7858 in model 2$)$ and overall accuracy ratio (0.6617 in model 1 versus 0.7182 in model 2). Overall, these results imply that the firm-specific fundamental factors summarized by the F-score seem to have a high power to predict default risks. Although the financial (accounting) variables used in computing the F-score and Z-score are similar (see Section 3 for definitions of the two scores in detail), the formula for the two scores exhibits different measurements for the financial variables. Specifically, the F-score pays attention to the "changes" in the financial variables over the two consecutive periods, while the Z-score focuses on the "levels" of the financial variables in each period. The evaluation statistics in Table 3 seem to suggest that the changes in firm-specific 
fundamentals (as captured by the F-score) are relatively more important than the levels of firm-specific fundamentals (as captured by the Z-score) in forecasting bankruptcy risks.

The estimation result for model 3 highlights another interesting finding: a forward-looking economic outlook, as captured by recession probability forecasts, is also important for predicting default risks. The coefficient on recession forecast is significantly positive. An increase in the recession probability forecast tends to increase corporate default risks. Surprisingly, model 3 exhibits comparable and similar forecasting performance (in terms of the different evaluation statistics) as the Z-score model (model 1), although model 3 includes only economic outlook and firm size variables.

Our core model in Eq. (2) (or model 4) suggests that both firm-specific fundamental factors and economic outlook are important determinants of corporate default risks. On the one hand, the coefficients of the Z-score and F-score are significantly negative. Improvements in a firm's fundamentals tend to lower its bankruptcy risk. On the other hand, similar to model 3, the coefficient on recession forecast is significantly positive. Deterioration in economic outlook (with an increase in the likelihood of a recession occurring next year) tends to increase a firm's bankruptcy risk.

Model 4 further indicates that the interaction between firm-specific fundamental factors and economic outlook matters for predicting default risks. The coefficient on the interaction term (Z-score times recession forecast) is significantly negative. This implies that firms with stronger fundamentals (with a higher Z-score) may counterbalance the negative effect of economic recession on default risks. To illustrate this point in more detail, we derive the marginal effect of recession forecast on default risks implied by Eq. (2):

$\frac{\partial \pi_{t}^{i}}{\partial(\text { Recession_Forecast })_{t}}=\beta_{4}+\beta_{5}\left(Z_{-} \text {score }\right)_{t-1}^{i}$.

Based on the estimation result for model 4 , the marginal effect is then given by

$\frac{\partial \pi_{t}^{i}}{\partial(\text { Recession_Forecast })_{t}}=0.7124-0.1454\left(Z_{-} \text {score }\right)_{t-1}^{i}$.

Eq. (13) indicates that a recession forecast has both direct (positive) and indirect effects on corporate default risks. The indirect effect of recession depends on the firm's fundamentals (Z-score). Interestingly, the negative sign of the indirect effect implies that the overall effect of recession on default risks could be negative for firms with a Z-score greater than 4.90. In other words, firms with strong fundamentals can better weather an economic downturn, so they encounter a relatively lower risk of default than do firms with poor fundamentals.

Of the four models, model 4 outperforms the others in predicting corporate default risks. The goodness-of-fit in model 4 is three to four times more than that of models 1 and 3 . The forecast errors (as measured by the Brier score, LPS, and BIC) in model 4 are about $20-42 \%$ lower than those in models 1 and 3. As for the performance comparison between models 2 and 4, the goodness-of-fit of the latter is still $30 \%$ higher than that of the former, and the forecast errors of the latter are slightly lower (2-4\% smaller) than those of the former. Lastly, model 4 is relatively more effective in distinguishing between default and non-default signals than model 2 , as reflected by the AUC (0.8284 versus 0.7858$)$ and overall accuracy ratio $(0.7543$ versus 0.7182$)$.

\section{Out-of-sample Results}

It is well known that good in-sample estimation results do not necessarily imply satisfactory out-ofsample results. We further evaluate the out-of-sample performance of the four models. The firm-year data for 2008 and 2009 are used as the holdout sample for the out-of-sample analysis. As in the in-sample analysis, we use different evaluation statistics to assess the forecasting performance of the four models. Table 4 summarizes the out-of-sample estimation results. 
TABLE 4

OUT-OF-SAMPLE ESTIMATION RESULTS

\begin{tabular}{|c|c|c|c|c|}
\hline & Model 1 & Model 2 & Model 3 & Model 4 \\
\hline Pseudo R-squared & 0.0362 & 0.0434 & 0.0059 & 0.0719 \\
\hline Brier score & 0.0122 & 0.0105 & 0.0119 & 0.0115 \\
\hline LPS & 0.0631 & 0.0559 & 0.0648 & 0.0542 \\
\hline $\mathrm{BIC}$ & 592 & 450 & 619 & 463 \\
\hline AUC & 0.7554 & 0.7446 & 0.6920 & 0.8483 \\
\hline Overall accuracy ratio & 0.6802 & 0.6663 & 0.6254 & 0.7780 \\
\hline Number of observations & 3,967 & 3,230 & 4,067 & 3,229 \\
\hline
\end{tabular}

Notes: LPS stands for log probability score, BIC for Bayesian information criterion, and AUC for area under the receiver operating characteristic (ROC) curve.

Our core model in Eq. (2) (or model 4) still indicates better out-of-sample forecasting performance relative to the other three models. The goodness-of-fit of model 4 is $66-99 \%$ higher than that of models 1 and 2. Model 3 even suggests negligible explanatory power with almost zero pseudo R-squared. Model 4 also exhibits lower forecast errors than models 1 and 3. The LPS and BIC of model 4 are 14-25\% lower than those of models 1 and 3, while the Brier score of model 4 is 3-6\% lower than the corresponding score of the two models. Although models 2 and 4 seem to generate similar forecast errors (as measured by the Brier score, LPS, or BIC), the explanatory power of the latter is noticeably higher than that of the former (a pseudo R-squared of 0.0434 for model 2 compared with one of 0.0719 for model 4 ). Table 4 also indicates that model 4 is more capable of distinguishing between default and non-default signals than the other models (with a higher AUC and overall accuracy ratio). In sum, the out-of-sample analysis yields similar findings as the in-sample analysis. A forward-looking economic outlook (recession probability forecasts), firm-specific fundamental factors (Z-score and F-score), and their interaction all play significant roles in predicting corporate default risks.

\section{CONCLUSION}

An accurate forecast of corporate default risk is crucial for financial institutions to effectively quantify potential expected and unexpected borrower losses. This paper studies the determinants of default probability by simultaneously examining the roles of firm-specific fundamentals and economic outlook in predicting corporate default risks. It utilizes a logistic regression framework to incorporate firm-specific characteristics (both the F-score and Z-score), an economic outlook variable (recession probability forecast), and the interaction term between economic outlook and a firm's fundamentals. The empirical model is estimated using U.S. listed non-financial firms over the 1997-2009 sample period. The empirical findings suggest that economic outlook (captured by recession probability forecast), firmspecific fundamental factors (measured by both the Z-score and F-score), and the interaction between economic outlook and a firm's fundamentals all play statistically significant roles in predicting bankruptcy risks. The proposed model also exhibits high levels of goodness-of-fit and classification ability and low levels of forecast error relative to the other models under consideration.

We are updating the data and the analysis in the periods 2010 to 2019 in the second phase of the research. The current paper uses U.S. data to illustrate the idea that economic outlook, firm-specific fundamentals, and their interaction are important drivers of corporate bankruptcy risk. It would be interesting to investigate whether the hypothesis also holds true for non-financial firms listed in other countries such as Canada, France, Germany, and Japan. Another extension of the current study would be to use an alternative economic outlook variable (other than the recession probability forecast) to predict default risk. For example, the diffusion index forecast generated from Stock and Watson's (2002) dynamic factor model could be a good proxy variable for economic outlook. 


\section{ENDNOTES}

1. Technically, there are differences in the definitions of credit risk, default risk, and bankruptcy risk. Credit risk refers to a loss suffered by a party whereby the counterparty fails to meet its financial obligations to the party under the contract. Credit risk may also arise if there is an increasing risk of default by the counterparty throughout the duration of the contract. Default risk refers to the non-payment of interest and/or principal on a loan by the borrower to the lender. Bankruptcy risk involves taking possession of any collateral provided by the defaulting counterparty; in this case, the liquidation value of the collateral is insufficient to recover the full loss on default. In this paper, we do not distinguish among the three risks. Hence, the terms credit risk, default risk, and bankruptcy risk are used interchangeably to mean that the counterparty files for bankruptcy. This definition is consistent with the construction of data for the dependent variable used in our empirical analysis.

2. Some of the daily variables are converted into weekly frequency and then combined with the other weekly variables. The daily variables contain purely financial data such as interest rates on T-bills/T-bonds, money market interest rates, stock market indices, and exchange rates. The weekly variables include economic indicators such as jobless claims statistics, the insured unemployment rate, bank credits and loans, financial conditions, and corporate bond yields. Lai and $\mathrm{Ng}(2020)$ argue that a combined dataset with both daily and weekly variables captures more categories and may provide a more complete picture of economic conditions.

3. The average default rates for our sample firms in the 10 sectors over the 1997-2009 period are as follows: communications: $3.6 \%$; consumer discretionary: $2.2 \%$; consumer staples: $1.5 \%$; energy: $1.1 \%$; financials: $0.8 \%$; health care: $1.1 \%$; industrials: $1.4 \%$; materials: $1.8 \%$; technology: $1.3 \%$; and utilities: $0.5 \%$.

\section{REFERENCES}

Agrawal, K. (2015). Default prediction using Piotroski’s F-score. Global Business Review, 16(5S), 175S$186 \mathrm{~S}$.

Altman, E.I. (1968). Financial ratios, discriminant analysis and the prediction of corporate bankruptcy. Journal of Finance, 23(4), 589-609.

Altman, E.I. (1984). A further empirical investigation of the bankruptcy cost question. Journal of Finance, 39(4), 1067-1089.

Altman, E.I. (2000). Predicting financial distress of companies: Revisiting the Z-score and ZETATM Models. Mimeo.

Altman, E.I., Haldeman, R., \& Narayanan, P. (1977). ZETATM analysis: A new model to identify bankruptcy risk of corporations. Journal of Banking and Finance, 1(1), 29-54.

Altman, E., \& Sabato, G. (2007). Modelling credit risk for SMEs: Evidence from the US markets. ABACUS, 43(3), 1-48.

Altman, E., Sabato, G., \& Wilson, N. (2010). The value of non-financial information in small and mediumsized enterprise risk management. Journal of Credit Risk, 6(2), 1-33.

Amor-Tapia, B., \& Tascon, M.T. (2016). Separating winners from losers: Composite indicators based on fundamentals in the European context. Czech Journal of Economics and Finance, 66(1), 70-94.

Arslan, Ö., \& Karan, M.B. (2009). Credit risks and internationalization of SMEs. Journal of Business Economics and Management, 10(4), 361-368.

Bonfim, D. (2009). Credit risk drivers: Evaluating the contribution of firm level information and of macroeconomic dynamics. Journal of Banking \& Finance, 33(2), 281-299.

Brédart, X. (2014). Bankruptcy prediction model: The case of the United States. International Journal of Economics and Finance, 6(3), 1-7.

Choi, N.Y., \& Sias, R.W. (2012). Why does financial strength forecast stock returns? Evidence from subsequent demand by institutional investors. Review of Financial Studies, 25(5), 1550-1587.

Dainelli, F., Giunta, F., \& Cipollini, F. (2013). Determinants of SME credit worthiness under Basel rules: The value of credit history information. PSL Quarterly Review, 66(264), 21-47.

Filipe, S.F., Grammatikos, T., \& Michala, D. (2016). Forecasting distress in European SME portfolios. Journal of Banking and Finance, 64(1), 112-135. 
Geyfman, V., Wimmer, H., \& Rada, R. (2016). The use of accounting screens for separating winners from losers among the S\&P 500 stocks. Journal of Accounting and Finance, 16(1), 45-60.

Gupta, J., Wilson, N., Gregoriou, A., \& Healy, J. (2014). The effect of internationalisation on modelling credit risk for SMEs: Evidence from UK market. Journal of International Financial Markets, Institutions \& Money, 31, 397-413.

Hyde, C.E. (2014). An emerging markets analysis of the Piotroski F-score. JASSA The Finsia Journal of Applied Finance, 2, 25-30.

James, P., Cheh, J.J., \& Kim, I-W. (2014). A comparative analysis on performance of seven all star investment models. Pan-Pacific Journal of Business Research, 5(2), 23-36.

Krauss, C., Krüger, T., \& Beerstecher, D. (2015). The Piotroski F-Score: A fundamental value strategy revisited from an investor's perspective. Institut für Wirtschaftspolitik und Quantitative Wirtschaftsforschung (IWQW) Discussion Papers No. 13/2015.

Kuo, H.C., Wang, L.H., Sheu, H.J., \& Li, F.K. (2003). Credit evaluation for small and medium-sized enterprises by the examination of firm-specific financial ratios and non-financial variables: Evidence from Taiwan. Review of Pacific Basin Financial Markets and Policies, 6(1), 5-20.

Lai, H., \& Ng, E.C.Y. (2020). On business cycle forecasting. Frontiers of Business Research in China, $14(1), 1-26$

Mare, D.S. (2015). Contribution of macroeconomic factors to the prediction of small bank failures. Journal of International Financial Markets, Institutions and Money, 39, 25-39.

Muscettola, M. (2013). Leverage risk. The weight of borrowed capital distinguishes the solvency of firms: An empirical analysis on a sample of 4,500 Italian SMEs. International Journal of Economics and Finance, 5(12), 24-39.

Nam, C.W., Kim, T.S., Park, N.J., \& Lee, H.K. (2008). Bankruptcy prediction using a discrete-time duration model incorporating temporal and macroeconomic dependencies. Journal of Forecasting, 27(6), 493-506.

Nam, J.H., \& Jinn, T. (2000). Bankruptcy prediction: Evidence from Korean listed companies during the IMF Crisis. Journal of International Financial Management and Accounting, 11(3), 178-197.

Ng, E.C.Y., \& Lai, H. (2017). Predicting recessions using a flexible and inclusive modelling approach. Manuscript.

Ohlson, J.A. (1980). Financial ratios and the probabilistic prediction of bankruptcy. Journal of Accounting Research, 18(1), 109-131.

Pederzoli, C., Thoma, G., \& Torricelli, C. (2013). Modelling credit risk for innovative SMEs: The role of innovation measures. Journal of Financial Services Research, 44(1), 111-129.

Piotroski, J.D. (2000). Value investing: The use of historical financial statement information to separate winners from losers. Journal of Accounting Research, 38(Supplement), 1-41.

Piotroski, J.D., \& So, E.C. (2012). Identifying expectation errors in value/glamour strategies: A fundamental analysis approach. Review of Financial Studies, 25(9), 2841-2875.

Platt, H.D., \& Platt, M.B. (1990). Development of a class of stable predictive variables: The case of bankruptcy prediction. Journal of Business Finance and Accounting, 17(1), 31-51

Richardson, F.M, Kane, G.D., \& Lobingier, P. (1998). The impact of recession on the prediction of corporate failure. Journal of Business Finance and Accounting, 25(1-2), 167-186.

Shumway, T. (2001). Forecasting bankruptcy more accurately: A simple hazard model. Journal of Business, 74(1), 101-124.

Stock, J.H., \& Watson, M.W. (2002). Macroeconomic forecasting using diffusion indexes. Journal of Business \& Economic Statistics, 20(2), 147-162.

Tinoco, M.H., \& Wilson, N. (2013). Financial distress and bankruptcy prediction among listed companies using accounting, market and macroeconomic variables. International Review of Financial Analysis, 30, 394-419.

Wu, Y., Gaunt, C., \& Gray, S. (2010). A comparison of alternative bankruptcy prediction models. Journal of Contemporary Accounting \& Economics, 6, 34-45. 